RESPIRATORY PHYSIOLOGY

\title{
Effect of simulated commercial flight on oxygenation in patients with interstitial lung disease and chronic obstructive pulmonary disease
}

\author{
L M Seccombe, P T Kelly, C K Wong, P G Rogers, S Lim, M J Peters
}

Thorax 2004;59:966-970. doi: 10.1136/thx.2004.022210

See end of article for authors' affiliations

.....................

Correspondence to: $L M$ Seccombe, Department of Thoracic Medicine, Concord Repatriation General Hospital, Sydney, Australia; seccombel@ email.cs.nsw.gov.au

Received 29 January 2004 Accepted 25 April 2004
Background: Commercial aircraft cabins provide a hostile environment for patients with underlying respiratory disease. Although there are algorithms and guidelines for predicting in-flight hypoxaemia, these relate to chronic obstructive pulmonary disease (COPD) and data for interstitial lung disease (ILD) are lacking. The purpose of this study was to evaluate the effect of simulated cabin altitude on subjects with ILD at rest and during a limited walking task.

Methods: Fiffeen subjects with ILD and 10 subjects with COPD were recruited. All subjects had resting arterial oxygen pressure $\left(\mathrm{PaO}_{2}\right)$ of $>9.3 \mathrm{kPa}$. Subjects breathed a hypoxic gas mixture containing $15 \%$ oxygen with balance nitrogen for 20 minutes at rest followed by a 50 metre walking task. Pulse oximetry $\left(\mathrm{SpO}_{2}\right)$ was monitored continuously with testing terminated if levels fell below $80 \%$. Arterial blood gas tensions were taken on room air at rest and after the resting and exercise phases of breathing the gas mixture.

Results: In both groups there was a statistically significant decrease in arterial oxygen saturation $\left(\mathrm{SaO}_{2}\right)$ and $\mathrm{PaO}_{2}$ from room air to $15 \%$ oxygen at rest and from $15 \%$ oxygen at rest to the completion of the walking task. The ILD group differed significantly from the COPD group in resting $15 \%$ oxygen $\mathrm{SaO}_{2}$, $\mathrm{PaO}_{2}$, and room air $\mathrm{pH}$. Means for both groups fell below recommended levels at both resting and when walking on $15 \%$ oxygen.

Conclusion: Even in the presence of acceptable arterial blood gas tensions at sea level, subjects with both ILD and COPD fall below recommended levels of oxygenation when cabin altitude is simulated. This is exacerbated by minimal exercise. Resting sea level arterial blood gas tensions are similarly poor in both COPD and ILD for predicting the response to simulated cabin altitude.
$\mathrm{V}$ arious social, economic, and health trends have combined to increase the number of patients with lung disease who undertake short and long distance commercial flights. Our population is ageing, but many of this population have the financial means to travel and the real costs of commercial air travel have fallen over the past 25 years

This older population has an increased rate of pulmonary disease, with the most significant increase projected to be in chronic obstructive pulmonary disease (COPD). ${ }^{1}$ Even without an increase in incidence, the factors described above have led to more patients with other pulmonary disease including interstitial lung disease (ILD) contemplating long distance travel. The clinical question of whether flight is safe for an individual patient is frequently posed.

Fresh air intake and pressurisation of aircraft cabins are achieved by the engine taking in outside air which is compressed, cooled, and then bled into the cabin. ${ }^{2}$ Increasing the rate of airflow and pressurising cabins to a greater degree requires use of more fuel and increases running costs. There are strict specifications for the quality of cabin air-both for the flow of fresh air and cabin pressure. Commercial aircraft are required to be pressurised to a cabin pressure equivalent to an altitude of not more than $8000 \mathrm{ft}$ ( $2438 \mathrm{~m}$ ) under normal operating conditions. ${ }^{3}$ This equates to a pressure of inspired oxygen $\left(\mathrm{PIO}_{2}\right)$ that can be reproduced by an inspired oxygen fraction $\left(\mathrm{FIO}_{2}\right)$ of approximately $15.1 \%$ at sea level.

That this lower $\mathrm{PIO}_{2}$ is associated with a fall in arterial oxygen pressure $\left(\mathrm{PaO}_{2}\right)$ in normal subjects that is accentuated in patients with COPD is clear. ${ }^{45}$ International guidelines recommend that patients with a room air $\mathrm{PaO}_{2}$ of $>9.3 \mathrm{kPa}$ $(70 \mathrm{~mm} \mathrm{Hg}),{ }^{6}$ arterial oxygen saturation $\left(\mathrm{SaO}_{2}\right)$ or pulse oximetry $\left(\mathrm{SpO}_{2}\right)$ of $>95 \%,{ }^{8}$ or the ability to walk 50 metres unaided $^{68}$ are unlikely to experience significant in-flight hypoxaemia. For borderline cases, laboratory tests can simulate cabin altitude using a gas mixture of $15.1 \%$ oxygen at rest where $\mathrm{a}^{\mathrm{PaO}_{2}}$ of $>6.7-7.3 \mathrm{kPa}(50-55 \mathrm{~mm} \mathrm{Hg})^{6-9}$ or $\mathrm{SaO}_{2}$ or $\mathrm{SpO}_{2}$ of $\geqslant 85 \%^{8}$ is regarded as acceptable. Supplemental oxygen is suggested for those who fall below these levels.

Concern that simulated hypoxia under resting conditions does not adequately reproduce the stresses of flight has led some investigators to include a modest exercise stress to simulate cabin movement. ${ }^{510}$ This is important in light of recent recommendations aimed to reduce the incidence of venous thrombosis and pulmonary embolism on longer flights. These encourage an increase in both physical movement and fluid intake that should lead to more lavatory visits.

COPD is not the only lung disease that needs to be considered in relation to flight safety. It may not be safe to presume that guidelines based on patients with COPD are also appropriate for those with interstitial lung disease (ILD). The increase in cardiac output with increased ventilation/ perfusion mismatch that occurs with exercise, as with ILD, may be produced under flight conditions. Resting pulmonary function and resting blood gas measurements may not be a good indicator of potential impairment under stress. 

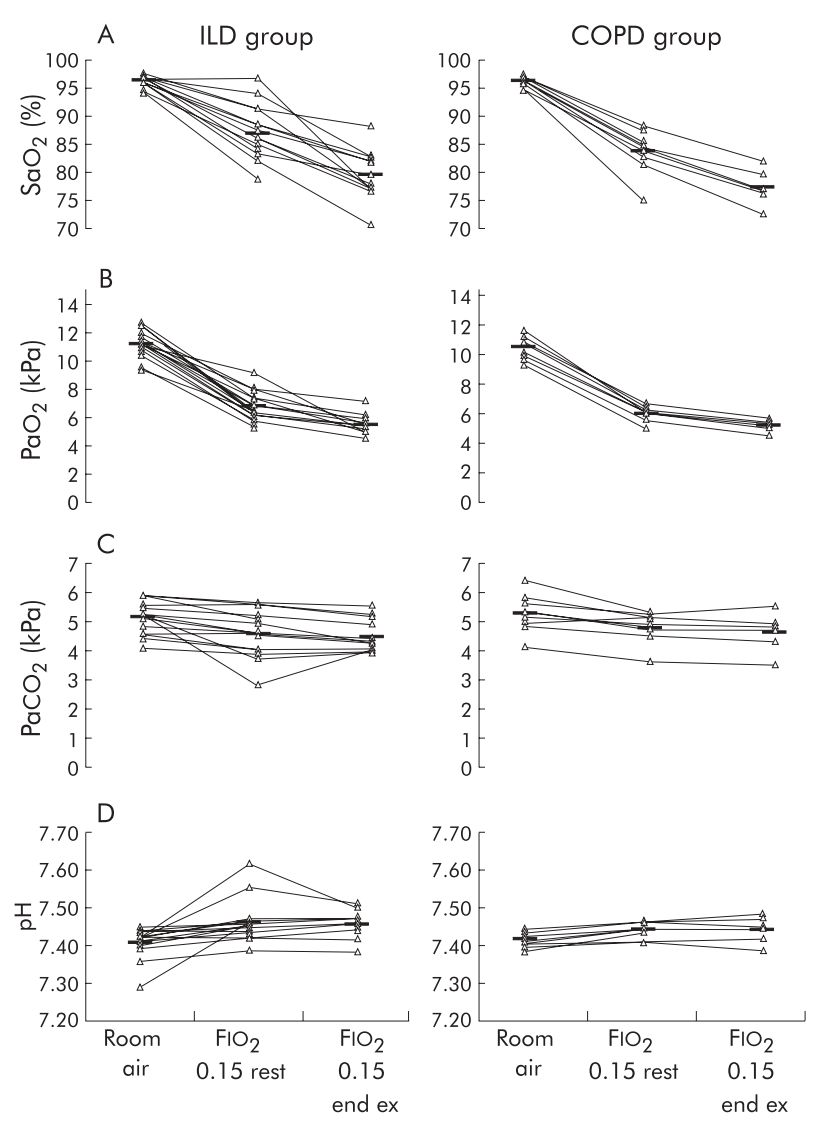

Figure 1 Comparison of arterial blood gas tensions between patients with interstitial lung disease (ILD) and those with chronic obstructive pulmonary disease (COPD) at sea level at rest (room air), on 15\% oxygen at rest for 20 minutes $\left(\mathrm{FiO}_{2} 0.15\right.$ rest), and after a walking task on $15 \%$ oxygen $\left(\mathrm{FIO}_{2} \mathrm{O} .15\right.$ end ex). Individual and mean values of (A) arterial oxygen saturation $\left(\mathrm{SaO}_{2}\right),(\mathrm{B})$ arterial oxygen pressure $\left(\mathrm{PaO}_{2}\right),(\mathrm{C})$ arterial carbon dioxide pressure $\left(\mathrm{PaCO}_{2}\right)$, and $(\mathrm{D})$ arterial $\mathrm{pH}$.

The purpose of this study was to evaluate the effect of simulated cabin altitude on subjects with ILD at rest and during a specific walking task. Patients with COPD were included for reference to the existing evidence base. We sought to determine whether there were features of resting lung function and arterial gas measurements that were predictive of the effect of flight simulation.

\section{METHODS}

\section{Subjects}

Fifteen patients with ILD and 10 patients with COPD were recruited with the consent of their physician. ILD was confirmed by high resolution computed tomography (HRCT) by a respiratory physician (bibasilar reticular abnormalities) combined with abnormal lung function (evidence of restriction and/or impaired gas exchange) in accordance with international consensus. ${ }^{11}$ COPD was classified according to ATS criteria. ${ }^{12}$ Patients were excluded from further study if their resting $\mathrm{PaO}_{2}$ was $<9.3 \mathrm{kPa}$ or both $\mathrm{SpO}_{2}$ and $\mathrm{SaO}_{2}$ were $<95 \%$. All patients were studied when were clinically stable and able to walk between testing facilities unaided, 100 metres (level) by the shortest route.

\section{Questionnaire}

The questionnaire asked the subjects when they last flew on an aircraft and if they experienced any breathlessness, headache, dizziness, or other symptoms. It also asked if they had plans to fly in the near future and, if yes, the duration of the expected flight. It asked if they drink alcohol or caffeinated drinks while in flight and how frequently they visited the lavatory. Finally, it asked whether the subject was aware that there is "less oxygen" in pressurised aircraft.

\section{Lung function}

Sitting spirometric tests and single breath transfer factor for carbon monoxide (TLCO) (Sensormedics Vmax, Yorba Linda, CA, USA) were performed according to ATS criteria. ${ }^{13}{ }^{14}$ Predicted values were derived from the recommendations of the European Community for Coal and Steel. ${ }^{15}$

\section{Altitude simulation test}

All studies were performed at sea level using a technique similar to that developed by Gong et al. ${ }^{16}$ After being seated for approximately 20 minutes, a radial arterial blood gas sample ("room air") was taken. The arterial blood sample was placed in an ice slurry before being analysed within 30 minutes of extraction (CD800, Chiron Diagnostics, Halstead, UK) which was calibrated twice daily.

Subjects then inhaled a hypoxic gas mix of $15 \%( \pm 0.2 \%)$ oxygen, balance nitrogen (BOC Gases, Australia). Subjects breathed through a two way, non-rebreathing valve (T-shape 2700, Hans Rudolph Inc, Kansas City, MO, USA) from a reservoir (30 litre non-diffusing gas collection bag; Hans Rudolph Inc) for 20 minutes while seated. A second arterial

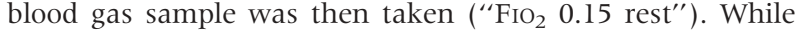
inhaling the same gas mixture, the subject was then asked to

\begin{tabular}{|c|c|c|c|}
\hline & Mean (SD) & Range & $\begin{array}{l}\text { Mean (SD) } \\
\% \text { predicted }\end{array}$ \\
\hline Age (years) & $\begin{array}{l}70(12) \\
70(9)\end{array}$ & $\begin{array}{l}52-86 \\
58-89\end{array}$ & - \\
\hline $\mathrm{BMI}$ & $\begin{array}{l}27.1(4.1) \\
25.4(4.9)\end{array}$ & $\begin{array}{l}20.8-35.4 \\
16.5-30.9\end{array}$ & - \\
\hline $\mathrm{FEV}_{1}$ (l) & $\begin{array}{l}1.83(0.55) \\
1.21(0.41)\end{array}$ & $\begin{array}{l}1.30-3.01 \\
0.65-1.76\end{array}$ & $\begin{array}{l}79(31) \\
45(13)\end{array}$ \\
\hline FVC (I) & $\begin{array}{l}2.33(0.78) \\
2.85(0.76)\end{array}$ & $\begin{array}{l}1.54-4.21 \\
1.61-3.85\end{array}$ & $\begin{array}{l}77(27) \\
83(16)\end{array}$ \\
\hline $\mathrm{FEV}_{1} / \mathrm{FVC}(\%)$ & $\begin{array}{l}80(8) \\
42(9)\end{array}$ & $\begin{array}{l}67-94 \\
31-56\end{array}$ & - \\
\hline $\mathrm{TLCO}(\mathrm{mmol} / \mathrm{kPa} / \mathrm{min})$ & $\begin{array}{l}3.5(0.9) \\
3.8(1.0)\end{array}$ & $\begin{array}{l}1.8-5.0 \\
2.2-5.0\end{array}$ & $\begin{array}{l}45(9) \\
49(14)\end{array}$ \\
\hline $\mathrm{TL} / \mathrm{VA}_{\mathrm{A}}(\mathrm{mmol} / \mathrm{kPa} / \mathrm{min} / \mathrm{l})$ & $\begin{array}{l}1.08(0.35) \\
0.83(0.24)\end{array}$ & $\begin{array}{l}0.72-2.01 \\
0.45-1.28\end{array}$ & $\begin{array}{l}61(18) \\
50(14)\end{array}$ \\
\hline
\end{tabular}


Table 2 Comparison of mean (SD) arterial blood gas tensions between 15 patients with interstitial lung disease (ILD) and 10 with chronic obstructive pulmonary disease (COPD) at sea level at rest (room air), on 15\% oxygen at rest for 20 minutes (FIO 2 0.15 rest), and after a walking task on $15 \%$ oxygen $\left(\mathrm{FlO}_{2} 0.15\right.$ end ex)

\begin{tabular}{|c|c|c|c|c|c|c|}
\hline & \multicolumn{3}{|l|}{ ILD } & \multicolumn{3}{|l|}{ COPD } \\
\hline & Room air & $\mathrm{FiO}_{2} 0.15$ rest & $\mathrm{F}_{10} 0.15$ end ex§ & Room air & $\mathrm{F}_{10} \mathrm{O}_{2} 0.15$ rest & $\mathrm{FlO}_{2} 0.15$ end exई \\
\hline $\begin{array}{l}\mathrm{SaO}_{2}(\%) \\
\mathrm{PaO}_{2}(\mathrm{kPa}) \\
\mathrm{PacO}_{2}(\mathrm{kPa}) \\
\mathrm{pH}\end{array}$ & $\begin{array}{l}96.3(0.9) \\
11.2(0.9) \\
5.1(0.6) \\
7.41(0.04)\end{array}$ & $\begin{array}{l}87.0(4.8) \ddagger \\
6.8(1.0) \ddagger \\
4.6(0.8) \ddagger \\
7.46(0.06) \ddagger\end{array}$ & $\begin{array}{l}79.5(4.4) \dagger \\
5.5(0.7) \dagger \\
4.5(0.6) \\
7.46(0.03)\end{array}$ & $\begin{array}{l}95.7(0.9) \\
10.5(0.7) \\
5.3(0.6) \\
7.42(0.02)^{*}\end{array}$ & $\begin{array}{l}83.2(3.7) \ddagger^{*} \\
6.1(0.5) \ddagger^{*} \\
4.8(0.5) \ddagger \\
7.44(0.02) \ddagger\end{array}$ & $\begin{array}{l}76.8(3.2) \dagger \\
5.3(0.4) \dagger \\
4.6(0.7) \\
7.44(0.03)\end{array}$ \\
\hline
\end{tabular}

$\mathrm{SaO}_{2}$, arterial oxygen saturation; $\mathrm{PaO}_{2}$, arterial oxygen pressure; $\mathrm{PaCO}_{2}$, arterial carbon dioxide pressure.

*ILD $\vee$ COPD ( $p<0.05$, unpaired $t$ test).

$+\mathrm{FIO}_{2} 0.15$ rest $v \mathrm{FiO}_{2}$ end ex $(\mathrm{p}<0.005$, paired $t$ test $)$

$\ddagger$ Room air $v \mathrm{FlO}_{2} 0.15$ rest ( $p<0.005$, paired $t$ test).

$\S n=12$ for ILD, $n=6$ for COPD.

stand and walk on a treadmill (Trackmaster TM500-E, Carrollton, TX, USA) set at the slowest speed $(16 \mathrm{~m} / \mathrm{min})$ for 50 metres (maximum of 3 minutes 8 seconds). The subject was then seated and a third arterial blood gas sample was taken ("FIO 20.15 end ex") within 30 seconds of exercise cessation.

$\mathrm{SpO}_{2}$ (Quartz Q-400, Louiseville, IO, USA) and a 12-lead electrocardiogram (ECG) (Cardioperfect, Sesamed, Delft, The Netherlands) were monitored continuously throughout the study and until recovery was complete. Perceived breathlessness (Borg scale $)^{17}$ was recorded at rest and every 5 minutes during the resting phase of the altitude simulation test. If $\mathrm{SpO}_{2}$ fell below $80 \%$ at any time during monitoring, an arterial blood gas measurement was immediately taken and testing ceased. Supplemental oxygen, resuscitation equipment, and medical personnel were available at all times.

The study was approved by the Central Sydney Area Health Service ethics review board with formal written consent obtained from all subjects.

\section{Statistical analysis}

Results were expressed as mean (SD). All continuous variables met tests for normal distribution. No $\mathrm{SpO}_{2}$ values reached $100 \%$ and were therefore considered as continuous. Paired $t$ tests were used for within subject comparisons and the Mann-Whitney test was used when data were not available in the second group. Comparisons of the ILD and COPD patients were performed using unpaired $t$ tests.

The critical time-30 seconds to sample after exercisewas not met in two patients with COPD and one with ILD; these results were therefore not included in the analysis of the last sample " $\mathrm{FIO}_{2} 0.15$ end ex". Subjects who terminated early during " $\mathrm{FIO}_{2}$ 0.15 rest" were included in the second sample data analysis. Those who terminated early during the
50 metre walking task were included with those who completed it.

Using two tailed comparisons, a p value of $<0.05$ was considered significant.

\section{RESULTS}

Fifteen subjects with ILD ( 11 men) and 10 with COPD (nine men) were studied. The demographic and lung function data of the study subjects are shown in table 1 .

Individual arterial blood gas tensions and mean values are shown in fig 1 . Mean (SD) values and statistical significance using paired or unpaired $t$ tests as applicable are presented in table 2 .

The mean size (with 95\% confidence intervals) of the changes in oxygenation are shown in table 3.

Due to pre-determined test termination, if $\mathrm{SpO}_{2}$ fell below $80 \%$, two ILD and one COPD subject did not complete 20 minutes resting $\mathrm{FIO}_{2}$ 0.15. Only three COPD and five ILD subjects completed the 50 metre exercise task. Subjects who survived the $\mathrm{SpO}_{2}>80 \%$ criteria were plotted on a survival curve (fig 2). Individual test end points, lowest $\mathrm{SaO}_{2}$, and whether they had recently flown are shown in table 4.

Linear regression analysis is presented in fig 3 with individual residuals plotted. From our data, the $\mathrm{PaO}_{2}$ at $\mathrm{FIO}_{2}$ 0.15 can be calculated from a $\mathrm{PaO}_{2}$ collected at sea level $\left(\mathrm{FiO}_{2}\right.$ 0.21 ) according to the following formula:

$$
\begin{aligned}
& \mathrm{PaO}_{2} \mathrm{FIO}_{2} 0.15=\mathrm{PaO}_{2} \mathrm{FIO}_{2} 0.21 \text { * } 0.54+4.7 \\
& R^{2}=0.27(\mathrm{p}<0.008)
\end{aligned}
$$

Fifty two percent of our subjects had flown in the last 2 years, $80 \%$ in the last 5 years. Approximately half of the subjects reported drinking alcohol (48\%), caffeinated drinks (64\%), and visiting the lavatory $(52 \%)$ during the flight. There were no reports of in-flight shortness of breath, headache, or

Table 3 Mean size and $95 \%$ confidence intervals $(95 \% \mathrm{Cl})$ of changes in arterial oxygen saturation $\left(\mathrm{SaO}_{2}\right)$ and arterial oxygen pressure $\left(\mathrm{PaO}_{2}\right)$ between values at sea level at rest (room air), on $15 \%$ oxygen at rest for 20 minutes $\left(\mathrm{FiO}_{2} 0.15\right.$ rest), and after a walking task on $15 \%$ oxygen $\left(\mathrm{FIO}_{2} 0.15\right.$ end ex) in 15 subjects with interstitial lung disease (ILD) and 10 with chronic obstructive pulmonary disease (COPD)

\begin{tabular}{lll} 
& $\begin{array}{l}\text { Room air }-\mathrm{FiO}_{2} 0.15 \text { rest } \\
(95 \% \mathrm{CI})\end{array}$ & $\begin{array}{l}\mathrm{FiO}_{2} \mathrm{O} .15 \text { rest }-\mathrm{FiO}_{2} \text { end ex } \\
(95 \% \mathrm{Cl})\end{array}$ \\
\hline $\begin{array}{l}\mathrm{SaO}_{2}(\%) \\
\mathrm{ILD}\end{array}$ & $\begin{array}{l}7.8(5.5 \text { to } 10.1) \\
\mathrm{COPD}\end{array}$ & $\begin{array}{l}9.3(6.8 \text { to } 11.7) \\
\mathrm{PaO}_{2}(\mathrm{kPa})\end{array}$ \\
$\mathrm{ILD}$ & $12.5(10.2$ to 14.8$)$ & \\
$\mathrm{COPD}$ & $4.4(3.8$ to 5.0$)$ & $1.5(0.9$ to 2.2$)$ \\
\hline
\end{tabular}




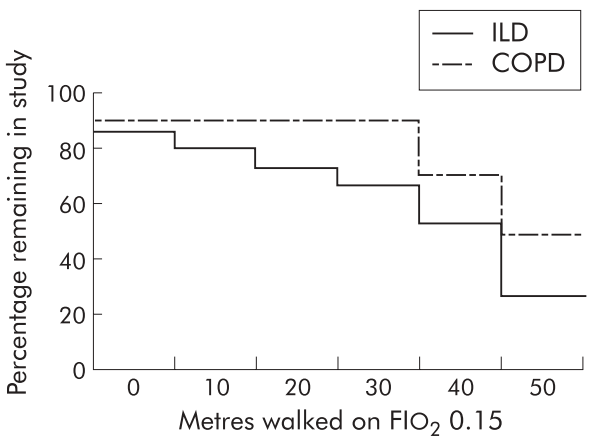

Figure 2 Curve plotting subject survival by $>80 \%$ saturation by pulse oximetry $\left(\mathrm{SpO}_{2}\right)$ during a walking task on $15 \%$ oxygen $\left(\mathrm{FIO}_{2} \mathrm{0.15}\right)$.

dizziness, but there were two reports of "fatigue" attributed to air travel. Fifty four percent were planning to fly in the near future and 64\% were unaware of "lower oxygen levels" on aircraft.

During "room air" and " $\mathrm{FIO}_{2} 0.15$ rest" there was no significant increase in Borg scale for COPD but there was for patients in the ILD group $(\mathrm{p}=0.02)$.

Eighty eight percent of subjects passed all resting fit to fly guidelines with regard to $\mathrm{PaO}_{2}, \mathrm{SpO}_{2}$ or $\mathrm{SaO}_{2}$, and ambulatory status. The $\mathrm{PaO}_{2}$ of all subjects fell below $7.3 \mathrm{kPa}$ and in $96 \%$ of cases it fell below $6.7 \mathrm{kPa}$ while performing a mild exercise task on $15 \%$ oxygen. In $80 \%$ of subjects the $\mathrm{PaO}_{2}$ fell below $7.3 \mathrm{kPa}$ at rest on $15 \%$ oxygen.

\section{DISCUSSION}

Predicting adverse consequences associated with hypoxia during a commercial flight is important. Patients with lung disease are concerned about health consequences and commercial airlines are concerned for their passengers, but also the economic costs and inconveniences associated with flight diversions. The results suggest that the degree of hypoxaemia under simulated cabin conditions cannot be predicted with confidence from resting measures. Furthermore, some subjects who under current guidelines do not warrant simulation testing, experience marked hypoxaemia when this is performed. Finally, some subjects who have flown without adverse effects can be shown to become markedly hypoxic during a simulation.

The data from subjects with COPD are in keeping with earlier studies which found that patients with COPD and mean $\mathrm{PaO}_{2}$ above $9.3 \mathrm{kPa}$ at sea level develop mean values that fall below $7.3 \mathrm{kPa}$ when exposed to normobaric hypoxia or hypobaria comparable to $8000 \mathrm{ft}^{.5}{ }^{1018} 19$ When a minimal exercise challenge was added-either an incremental bicycle task ${ }^{10}$ or a stepping task ${ }^{5}$ - there was a further fall in $\mathrm{PaO}_{2}$ of $1-1.5 \mathrm{kPa}$. None of these studies states whether the subjects had flown with or without adverse event. Our primary reason for inclusion of this group was to have a reference for our simulation test to this evidence base and to the existing guidelines.

A recent study has studied the effect of hypobaric hypoxia on patients with restrictive lung disease. ${ }^{20}$ However, while this study included some subjects with ILD, it also included others with a variety of other forms of restrictive lung disease. It is therefore difficult to establish direct comparability with our data. For all that, the results showed a similar response to this study at resting hypobaria equivalent to $8000 \mathrm{ft}$ (mean $6.5 \mathrm{kPa}$ ) with a further fall to $5.1 \mathrm{kPa}$ after a cycle task.

On standard measures of disease severity, the COPD group had more severe disease. We did not seek to recruit cohorts with similar severity as these are essentially incomparable disease processes. It can be said that the gas exchange

\begin{tabular}{|c|c|c|c|c|}
\hline $\begin{array}{l}\text { Flight in past } \\
2 \text { years }\end{array}$ & $\begin{array}{l}\text { Baseline } \\
\mathrm{SaO}_{2}\end{array}$ & $\begin{array}{l}\text { End rest } \\
\mathrm{FiO}_{2} 0.15 \mathrm{SaO}_{2}\end{array}$ & $\begin{array}{l}\text { Extent of study } \\
\text { reached on } \\
\mathrm{FiO}_{2} 0.15\end{array}$ & Lowest $\mathrm{SaO}_{2}$ \\
\hline \multicolumn{5}{|l|}{ COPD } \\
\hline No & 94.3 & 74.4 & $8 \mathrm{~min}$ at rest & 74.4 \\
\hline No & 95.9 & 84.3 & $20 \mathrm{~min}$ at rest & 84.3 \\
\hline Yes & 94.3 & 83.1 & $20 \mathrm{~m}$ walk & 76.0 \\
\hline Yes & 96.1 & 82.1 & $30 \mathrm{~m}$ walk & 75.7 \\
\hline Yes & 96.9 & 84.0 & $30 \mathrm{~m}$ walk & 76.3 \\
\hline No & 95.7 & 85.0 & $40 \mathrm{~m}$ walk & $79^{*}$ \\
\hline No & 95.3 & 80.8 & $40 \mathrm{~m}$ walk & 72.0 \\
\hline Yes & 95.7 & 84.0 & Complete $50 \mathrm{~m}$ walk & 79.1 \\
\hline Yes & 96.6 & 86.7 & Complete $50 \mathrm{~m}$ walk & $80^{*}$ \\
\hline Yes & 96.4 & 87.8 & Complete $50 \mathrm{~m}$ walk & 81.4 \\
\hline \multicolumn{5}{|l|}{ ILD } \\
\hline Yes & 94.3 & 78.8 & $12 \mathrm{~min}$ at rest & 78.8 \\
\hline Yes & 97.2 & 84.2 & $19 \mathrm{~min}$ at rest & 84.2 \\
\hline No & 96.7 & 86.0 & $10 \mathrm{~m}$ walk & 77.9 \\
\hline Yes & 96.8 & 86.2 & $20 \mathrm{~m}$ walk & 77.3 \\
\hline No & 95.9 & 82.3 & $30 \mathrm{~m}$ walk & $83^{*}$ \\
\hline No & 96.4 & 96.6 & $30 \mathrm{~m}$ walk & 77.1 \\
\hline Yes & 97.5 & 91.3 & $40 \mathrm{~m}$ walk & 77.1 \\
\hline No & 96.2 & 82.0 & $40 \mathrm{~m}$ walk & 70.7 \\
\hline No & 96.7 & 94.1 & $40 \mathrm{~m}$ walk & 82.9 \\
\hline Yes & 94.5 & 85.0 & $40 \mathrm{~m}$ walk & 76.7 \\
\hline Yes & 97.1 & 88.3 & Complete $50 \mathrm{~m}$ walk & 81.9 \\
\hline No & 96.7 & 91.3 & Complete $50 \mathrm{~m}$ walk & 88.2 \\
\hline No & 96.2 & 83.3 & Complete $50 \mathrm{~m}$ walk & 79.6 \\
\hline Yes & 96.2 & 82.3 & Complete $50 \mathrm{~m}$ walk & 82.3 \\
\hline No & 96.0 & 88.5 & Complete $50 \mathrm{~m}$ walk & 82.8 \\
\hline
\end{tabular}



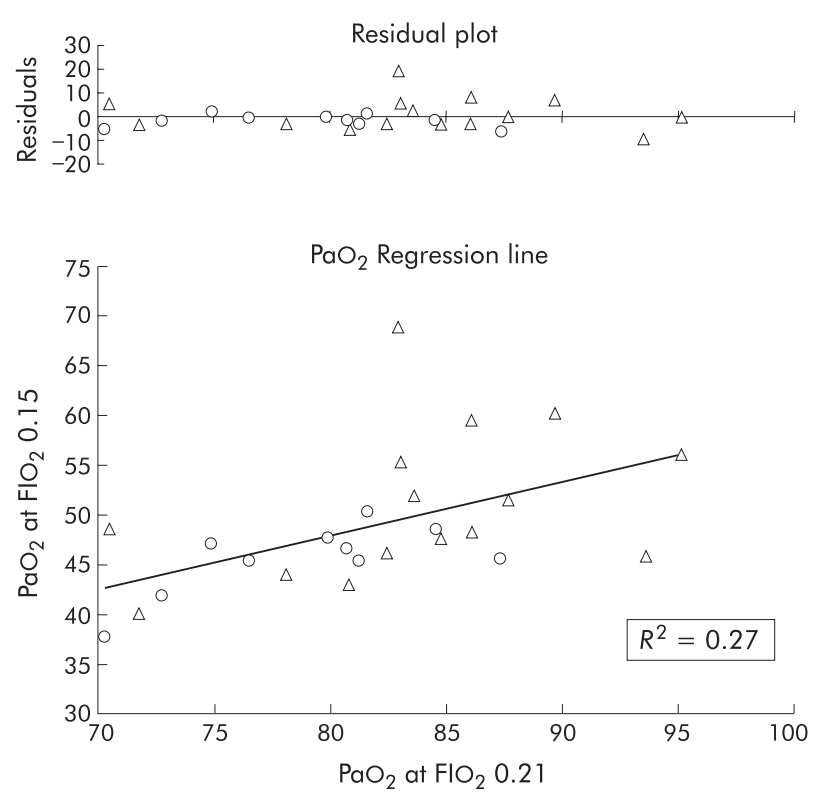

Figure 3 Plot of arterial oxygen pressure $\left(\mathrm{PaO}_{2}\right)$ at $15 \%$ oxygen at rest $\left(\mathrm{FlO}_{2} 0.15\right)$ against $\left.\mathrm{PaO}_{2}\right)$ at sea level $\left(\mathrm{FiO}_{2} \mathrm{0.21}\right)$ with residuals for individual subjects with interstitial lung disease (triangles) and chronic obstructive pulmonary disease (circles). Regression (solid line): $\mathrm{PaO}_{2} \mathrm{FIO}_{2}$ $0.15=\mathrm{PaO}_{2} \mathrm{FlO}_{2} 0.21 * 0.54+4.7$.

abnormality, as assessed by measurement of carbon monoxide transfer factor, was similar. Resting blood gas tensions and the frequency and extent of hypoxia were similar for COPD and ILD subjects, but the COPD group experienced greater desaturation while breathing the hypoxic gas at rest.

Most of our subjects passed current resting fitness to fly guidelines. ${ }^{6-9}$ Only three subjects would have warranted further investigation by one guideline due to borderline pulse oximetry measures with an additional risk factor. ${ }^{8}$ However, the majority of subjects proceeded to "fail" the altitude simulation test at rest and almost all the remainder fell below an acceptable level of oxygenation when a minor exercise task was added. In-flight emergencies are rare; COPD is common. It is therefore reasonable to suggest that many similar patients fly now and do so without acute adverse events. We therefore do not advocate wider screening of patients who have ILD or COPD with an altitude simulation test until treatment decisions based on the simulation test can be better validated. More and better information on the clinical characteristics of patients with lung disease who do experience problems during flight is required. As these events are rare, this may be best achieved with a central register that would then be analogous to some of the rare congenital malformation databases. It would be in the interests of airlines to provide relevant information in relation to the cabin air conditions, particularly pressurisation schedules on the flight in question.

Approaching the problem from the other end, prospective evaluation of a large number of patients with lung disease who plan to fly is also required. This evaluation could be simple-limited to diagnosis and resting blood gas estimation. It should be correlated with the travel itinerary and any subsequent adverse events experienced. Altitude simulation studies are time consuming and only a subset of such patients could have a formal altitude simulation test. Significant clinical and ethical issues may well arise in patients who volunteer for such a study.

After careful consideration in conjunction with our institutional ethics committee, we resolved not to inform subjects in this study of their individual test results. To do so might have generated concern about the risks of flying when the magnitude of that risk was uncertain. Furthermore, there may be implications for travel insurance. In this study the limits of this "no tell" policy were not tested by what might be considered extreme hypoxia $\left(\mathrm{PaO}_{2}\right.$ below $6.7 \mathrm{kPa}$ in any subject). Presumably, any clinical centre would have to define policies for dealing with research subjects and the parameters outside which more complex evaluation or inflight oxygen was recommended.

In summary, hypoxaemia considered severe enough to put a patient with ILD at risk during a commercial air flight cannot be accurately predicted from resting blood gas determination at rest. This exposes some limitation in the evidence base used to inform patients with lung disease of the potential hazards of commercial flights. While further data are accrued, we recommend that the existing guidelines be followed in relation to prediction and minimisation of these risks.

\section{Authors' affiliations}

L M Seccombe, P T Kelly, C K Wong, P G Rogers, S Lim, M J Peters, Concord Repatriation General Hospital, Sydney, Australia

\section{REFERENCES}

1 Murray CJL, Lopez AD. Evidence-based health policy - lessons from the Global Burden of Disease Study. Science 1996;274:740-3.

2 Rayman RB. Cabin air quality: an overview. Aviat Space Environ Med 2002;73:211-5.

3 Code of Federal regulations. Title 14, part 25.841 Washington: US Government Printing Office, 1986.

4 Dillard T, Rajagopal K, Slivka W, et al. Lung function during moderate hypobaric hypoxia in normal subjects and patients with chronic obstructive pulmonary disease. Aviat Space Environ Med 1998;69:979-85.

5 Naughton M, Rochford P, Pretto J, et al. Is normobaric simulation of hypobaric hypoxia accurate in chronic airflow limitation? Am J Respir Crit Care Med 1995; 152:1956-60

6 Aerospace Medical Association, Air Transport Medicine Committee, Alexandria. Medical guidelines for air travel. Aviat Space Environ Med 1996;67:B1-16.

7 Lien D, Turner M, the Canadian Thoracic Society Standards Committee. Recommendations for patients with chronic respiratory disease considering air travel: a statement from the Canadian Thoracic Society. Can Respir J 1998;5:95-100.

8 British Thoracic Society Standards of Care Committee. Managing passengers with respiratory disease planning air travel: British Thoracic Society recommendations. Thorax 2002;57:289-304.

9 American Thoracic Society. Standards for the diagnosis and care of patients with chronic obstructive pulmonary disease. Am J Respir Crit Care Med 1995; 152:S78-83.

10 Christensen CC, Ryg M, Refvern OK, et al. Development of severe hypoxaemia in chronic obstructive pulmonary disease patients at $2438 \mathrm{~m}$ (8000 ft) altitude. Eur Respir J 2000; 15:635-9.

11 American Thoracic Society. Idiopathic pulmonary fibrosis: diagnosis and Treatment. Am J Respir Crit Care Med 2000;161:646-64.

12 Pauwels RA, Buist AS, Calverley PMA, et al, on behalf of the GOLD Scientific Committee. Global strategy for the diagnosis, management and prevention of chronic obstructive pulmonary disease. Am J Respir Crit Care Med 2001; 163:1256-76.

13 American Thoracic Society. Standardization of spirometry. Am J Respir Crit Care Med 1995;152:1107-36.

14 American Thoracic Society. Single-breath carbon monoxide diffusing capacity (transfer factor). Recommendations for a standard technique. Am J Respir Crit Care Med 1995; 152:2185-98.

15 European Community for Coal and Steel. Standardized lung function testing. Bull Eur Physiopathol Respir 1983;19(Suppl 5):7-21.

16 Gong H, Tashkin P, Enoch Y, et al. Hypoxia-altitude simulation test. Evaluation of patients with chronic airway obstruction. Am Rev Respir Dis 1984; 130:980-6.

17 Borg GA. Psychophysical bases of perceived exertion. Med Sci Sports Exerc 1982;14:377-81.

18 Dillard TA, Moores LK, Bilello KL, et al. The pre-flight evaluation. A comparison of the hypoxia inhalation test with hypobaric exposure. Chest 1995; 107:352-7.

19 Berg B, Dillard T, Rajagopal K, et al. Oxygen supplementation during air travel in patients with chronic obstructive lung disease. Chest 1992;101:638-41.

20 Christensen CC, Ryg MS, Refvern OK, et al. Effect of hypobaric hypoxia on blood gases in patients with restrictive lung disease. Eur Respir J 2002;20:300-5. 